\title{
A review of nephrotic syndrome and atopic diseases in children
}

\author{
Yue Zheng, Ling Hou, Xiu-Li Wang, Cheng-Guang Zhao, Yue Du \\ Department of Pediatrics, Shengjing Hospital of China Medical University, Shenyang, China \\ Contributions: (I) Conception and design: Y Du; (II) Administrative support: CG Zhao; (III) Provision of study materials or patients: L Hou; (IV) \\ Collection and assembly of data: XL Wang; (V) Data analysis and interpretation: Y Zheng; (VI) Manuscript writing: All authors; (VII) Final approval \\ of manuscript: All authors. \\ Correspondence to: Yue Du, PhD. Department of Pediatrics, Shengjing Hospital of China Medical University, No. 36 of Sanhao Street, Heping \\ District, Shenyang 110004, China. Email: drduyue24@163.com.
}

\begin{abstract}
Pediatric nephrotic syndrome (NS) is a common and recurrent glomerular disease in childhood. Furthermore, $50-70 \%$ of children with NS have increased total $\mathrm{IgE}$ in peripheral blood and a variety of clinical manifestations of atopic diseases. Hence, NS has many similarities with atopic diseases. However, no study has revealed a clear link between these two diseases. The present review discusses the correlation between pediatric NS and atopic diseases in children from three aspects: pathogenesis, cytokine change, and treatment. There are similar changes in $\mathrm{T}$ cells in terms of pathogenesis, with Th1/Th2 dysfunction and Treg cell function downregulation. Cytokine changes are similar and manifest as an increase in Th2 cytokines, TNF- $\alpha$ and TGF- $\beta 1$, and a decrease in IL-10. Glucocorticoids, immunosuppressants and biological agents are used for the treatment of these two diseases. Therefore, it was speculated that NS and atopic diseases may be the same kind of disease, have a similar pathogenesis, and only exhibit different clinical manifestations due to different affected parts of the disease.
\end{abstract}

Keywords: Pediatric; nephrotic syndrome (NS); atopic diseases; clinical manifestations; review

Submitted Feb 27, 2020. Accepted for publication Sep 04, 2020.

doi: 10.21037/tau-20-665

View this article at: http://dx.doi.org/10.21037/tau-20-665

\section{Introduction}

Pediatric nephrotic syndrome (NS) is a group of clinical syndromes, including severe proteinuria, hypoalbuminemia, hyperlipidemia, and edema. These are caused by the highly increased permeability of glomerular filtration barrier to plasma protein, and severe loss of a large amount of plasma protein from urine. The pathogenesis of this disease is not clear. However, in recent years, with the improvement of medical technology and more in-depth research, it was found that $50-70 \%$ of children with NS have increased total $\operatorname{IgE}$ in peripheral blood, and have clinical manifestations, such as airway hyperresponsiveness, skin pruritus, repeated eczema, and skin allergy. Hence, NS has many similarities with atopic diseases. However, no study has revealed a clear link between NS and atopic disease in children. This review discusses the correlation between NS and atopic diseases in children from three aspects (pathogenesis, cytokine change, and treatment) in order to identify the similarities between NS and atopic diseases in children and provide new clues and methods for the treatment of NS in children.

\section{An overview and pathogenesis of NS and atopic disease}

\section{An overview and pathogenesis of NS in children}

The most common pathological type of NS in children is a disorder with minimal changes. Most children are sensitive to steroid therapy, while some children have hormone dependence. The pathogenesis of minimal changes in NS children is not clear. To date, no single theory can completely explain its entire pathophysiological process. At present, it is considered that NS is mainly correlated to 
immune dysfunction, especially $\mathrm{T}$ cell dysfunction, which leads to the abnormal secretion of osmotic factors, such as cytokines or specific antibodies, and attacks podocytes, resulting in glomerular filtration membrane damage $(1,2)$.

According to the different cytokines secreted, helper $\mathrm{T}$ cells (Th) can be divided into three types: Th0, Th1, and Th2 cells. A previous study revealed that the pathogenesis of NS might be correlated to Th2 activation. Furthermore, NS patients commonly exhibit the downregulation of Th1 cells and the upregulation of Th2 cells, resulting in a Th1/Th2 imbalance, and this may be one of the important mechanisms of NS occurrence and development $(3,4)$. After undergoing further research, Dong et al. $(5,6)$ reported that Th17 cells may be correlated to renal tubular epithelial and renal interstitial damage, chronic inflammatory damage to the kidney, and renal fibrosis. Th17 cells are a subset of $\mathrm{T}$ cells, which mainly secretes interleukin (IL)-17. In addition, as important immunoregulatory cells, Treg also plays an important role in autoimmune diseases, transplant rejection, and tumors (7). Normally, Treg cells and Th17 cells maintain a balance between them. In NS, Treg expression decreases, and Th17 expression increases, and the Th17/Treg imbalance is involved in the development of NS (8).

Cellular immunity also plays an important role in the occurrence and development of NS. Humoral immunity, namely, the immune response involved in B cells and their secreted immunoglobulins, may also be involved in the process of immune regulation in NS. Peripheral blood $\operatorname{IgE}$ is significantly increased in NS children, especially in children with frequent relapses (9), and activated B cells are the main cells that produce antibodies. Hence, it could be speculated that B cells are involved in the pathogenesis of NS. This is also one of the bases for the conjecture that NS and atopic diseases are correlated.

\section{An overview of atopic disease and its pathogenesis}

Atopic disease is a chronic inflammatory immune disease mainly mediated by $\operatorname{IgE}$ and characterized by positive results of skin allergen tests or serum specific IgE, which include atopic dermatitis, allergic rhinitis, and asthma. Atopic disease is closely correlated to genetic and environmental factors. Therefore, an allergic constitution's tendency to produce IgE antibodies in response to common antigens in the environment is the basis of atopic diseases $(10,11)$.

Under the stimulation of allergens (such as dust mites, pollens, molds, etc.), the immune response mediated by
Th2 is enhanced in individuals with atopic constitutions, causing an imbalance in the proportion and function of THL/Th2. Th2 cells secrete a variety of cytokines (such as IL-4, IL-5, IL-6, IL-13, etc.) to promote the synthesis and secretion of $\operatorname{IgE}$ through $B$ cells, and this results in the occurrence of allergic diseases (12). In addition, Treg can reduce $\operatorname{IgE}$ production by inhibiting Th2 cells and regulating antibody subtypes produced by B cells $(13,14)$. However, the immunosuppressive function of Treg cells in patients with allergic constitutions remains defective. Therefore, the excessive release of IgE through B cells binds to a large number of $\mathrm{IgE}$ receptors on the surfaces of the nasal cavity, skin, and airway mucosa, which accordingly activate mast cells to release inflammatory mediators that mainly comprise of leukotrienes and histamines. These inflammatory mediators act on the nasal cavity, skin, and airway and other mucosae, and cause the corresponding symptoms $(15,16)$.

\section{Similarities of pathogenesis between NS and atopic disease in children}

As early as 1951, Fanconi et al. (17) reported that the occurrence of NS is correlated to an atopic constitution. Subsequently, there have been reports on the occurrence and recurrence of NS induced by exposure to pollen (18), mold (19), mosquito bites (20), and vaccination (21). Therefore, exposure to allergens may lead to the occurrence and recurrence of NS.

$\operatorname{IgE}$ is synthesized by B cells, which plays an important role in the occurrence and development of atopic diseases in children, such as asthma, allergic rhinitis, and atopic asthma. Furthermore, it has been considered that $\mathrm{IgE}$ is the basis of the pathogenesis of atopic diseases $(22,23)$. Many studies have revealed that the serum $\mathrm{IgE}$ level is significantly higher in NS children than in healthy age-matched children (24). In children with recurrent NS, the IgE level significantly increases, and there is a higher relapse rate when compared to the remission stage $(1,25)$. A study also revealed that the $\operatorname{IgE}$ level increased with the prolongation of NS development (26). This suggests that the atopic process is also involved in the development of NS.

In addition, by summarizing the pathogenesis of the two diseases, it was found that there are some similarities in $\mathrm{T}$ cell changes between NS and atopic diseases. Both have THL/Th2 dysfunction (that is, Th2-mediated immune enhancement and Th1-mediated immune weakening), which is accompanied by Treg cell function downregulation. Therefore, it was speculated that NS and atopic disease 
might have a similar immunological mechanism.

\section{Changes in cytokines in NS and atopic diseases}

\section{Changes in cytokines in NS}

As a small molecular weight-secreted protein with important physiological and pathological functions, cytokines can mediate many biological processes, and participate in the occurrence and development of many diseases.

Th1 cells mainly secrete interferon- $\gamma$ (INF- $\gamma$ ), tumor necrosis factor- $\alpha$ (TNF- $\alpha)$, IL-2, IL-12, and IL-23, and its function is primarily to play a role in inflammatory responses by activating phagocytes and neutrophils. Th2 cells mainly secrete IL-4, IL-5, IL-6, IL-10, and IL-13, and its function is to play an anti-inflammatory role by inducing the activation of eosinophils and B cells to synthesize and secrete $\operatorname{IgE}$ and antibodies (27-29). The inflammatory response and antiinflammatory effects are maintained in a balanced state in normal subjects. For the NS children mentioned in the above study, there was an over-activation of Th2, TH1/Th2 dysfunction, and changes in cytokine levels. In NS, Th2 cells are upregulated, and the levels of cytokines secreted by these, as well as IL-4 (30), IL-5 (31), IL-6 (32), and IL-13 (33,34), all increased. However, there was no significant increase in Th1 cytokines, such as IL-2 and IFN- $\gamma$, in NS (33).

Treg cells also secrete cytokines. TGF- $\beta$ is a cytokine with many biological functions, and its interaction with Treg cells is complex. Treg can secrete TGF- $\beta$, and while in a stable body state, TGF- $\beta$ can promote the production of Treg to inhibit inflammatory responses. However, in the presence of infection, TGF- $\beta$ inhibits the differentiation of $\mathrm{CD}^{+} \mathrm{T}$ cells into Treg cells and induces Th17 cell differentiation. This results in glomerulosclerosis, renal interstitial fibrosis, and increased permeability of the glomerular filtration membrane, which leads to the occurrence of NS. It is possible that in the presence of infection, the high levels of produced IL-6 have a synergistic effect with TGF- $\beta(35,36)$. Both Th2 cells and Treg cells can secrete IL-10. IL-10 has a negative immunomodulatory effect and is also a protective factor for NS. Furthermore, the level of IL-10 in NS patients is lower than in other subjects (31).

In addition, Th and Treg cells can secrete cytokines, monocyte-macrophages, epithelial cells, and mesangial cells in the kidneys and secrete TNF- $\alpha$. These cannot only induce damage to glomerular vascular endothelial cells and glomerular basement membrane epithelial cells but also destroy the charge barrier of the glomerular basement membrane, leading to protein loss (37). TNF- $\alpha$ levels increase in NS children $(33,38)$.

\section{Changes in cytokines in atopic diseases}

There are IgE-dependent immediate hypersensitivity reactions in all atopic diseases. For example, Th2 cytokines are dominantly expressed, and the levels of IL-4, IL-5, IL6 , and IL-13 increase in children with asthma and allergic rhinitis (39-42). Studies have revealed that the TGF- $\beta 1$ level in the airway of asthma is higher than that in healthy subjects (43), and this is the main regulatory factor of airway remodeling in asthma (44). Similarly, animal experiments have also confirmed that the TGF- $\beta 1$ level in allergic rhinitis rats is higher than in the control group, which can not only inhibit the inflammatory reaction but also remodel the airway tissue of the nasal mucosa (45). IL-10 can inhibit the production of inflammatory cells and $\mathrm{IgE}$ and protect the airway. Furthermore, IL-10 levels in peripheral blood are low in patients with asthmatic and allergic rhinitis (46). In addition, TNF- $\alpha$ can cause eosinophils to accumulate and adhere to vascular endothelial cells, and release cytotoxic substances to increase vascular permeability, resulting in local mucosal edema and damage. Its level in atopic diseases is significantly higher than that in normal subjects $(47,48)$.

\section{Similarities of cytokines between NS and atopic diseases}

IL-13 is a cytokine secreted by Th2 cells. A large number of studies have revealed that IL-13 levels significantly increased in NS children, especially in children with frequent relapses. Animal experiments have also confirmed that rats with a high expression of IL-13 may have NS. The mechanism may be that IL-13 receptors are present on the podocyte surface. Hence, IL-13 can directly act on podocytes, resulting in the rearrangement of the actin cytoskeleton of podocytes, the disappearance of the foot process, and the occurrence of proteinuria (49). Furthermore, IL-13 has also been proven to regulate the rearrangement of actin cytoskeletons in human nasal epithelial cells (50), which can remodel the nasal mucosa airway. Similarly, in the development of asthma, IL-13 can regulate the proliferation of bronchial fibroblasts, myofibroblasts, and airway smooth muscle cells, resulting in airway remodeling (51). Therefore, in both NS and atopic diseases, such as asthma and allergic rhinitis, IL-13 has a direct effect on target organs and can cause functional disorder and even disease by changing the target organ structure. 
IL-4 can also remodel the target organ structure $(51,52)$. Similar to IL-13, and in addition to its direct effects, IL-4 is an important transmission factor in the synthesis of $\mathrm{IgE}$ through B cells. Furthermore, the serum levels of IL-4, IL-13, and IgE are significantly elevated in NS and atopic diseases. Therefore, IL-4 and IL-13 may also be involved in the production of IgE in NS and atopic diseases.

The above-mentioned summaries reveal similarities between NS and atopic diseases in terms of cytokines (pediatric asthma, allergic rhinitis, and the acute stage of atopic dermatitis). All manifest as an increase in Th2 cytokines, TNF- $\alpha$ and TGF- $\beta 1$, and a decrease in IL10. Therefore, it was speculated that there were some similarities in the nature of these two diseases.

\section{Comparison of treatment schemes between NS and atopic disease in children}

\section{Summary of NS treatment}

Glucocorticoid is the first-line drug for NS $(53,54)$. However, for patients with refractory NS, immunosuppressants should be added in clinical practice.

Cyclophosphamide (CTX) is the oldest cytotoxic drug that inhibits cell division and proliferation by inhibiting DNA synthesis. It affects both B cells and T cells, but particularly B cells. Cyclosporine A (CsA) can inhibit IL-2 production by inhibiting the activity of calcineurin and interfering with $\mathrm{T}$ cell activation. Tacrolimus is a macrolide antibiotic, and its molecular structure and immune mechanism are the same as CsA, but the effect is better than CsA. Mycophenolate mofetil (MMF) inhibits lymphocyte proliferation by inhibiting the activity of hypoxanthine nucleoside monophosphate dehydrogenase. Therefore, it affects $\mathrm{T}$ and $\mathrm{B}$ cells $(55,56)$.

In recent years, there have been successive reports on the treatment of steroid dependence in refractory NS using a human-mouse chimeric monoclonal antibody (rituximab) specifically for B cell surface antigen CD20. The mechanism may be that the production of some pathogenic cytokines affected by B cells can be activated by eliminating $B$ cells (57-59), in order to maintain the normal function of the filtration barrier.

\section{Treatment of atopic diseases}

\section{Summary of treatment of atopic dermatitis}

In addition to basic treatments such as phototherapy, moisturizing, and cleaning, glucocorticoid remains the firstline treatment for atopic dermatitis. Calcineurin inhibitors, such as tacrolimus ointment, are chosen when the effect of glucocorticoids is not enough. At present, the systemic medication of atopic dermatitis is mainly antihistamines (60). However, for severe cases, glucocorticoids or other immunosuppressants such as cyclosporine, MMF, and azathioprine can be applied (61-63). The guidelines for the 2018 European consensus consider that systemic immunosuppressants, such as cyclosporin, methotrexate, azathioprine, and MMF, are the first choice for treating refractory atopic dermatitis.

In addition, it has been recently found that monoclonal anti-IgE antibody omalizumab (64), human-mouse chimeric monoclonal anti-CD20 antibody rituximab, and anti-IL-4/ IL-13 antibody dupilumab (65) can also achieve a good therapeutic effect.

A summary of the treatment of asthma in children (66) The treatment of asthma in children is mainly divided into acute stage treatment and maintenance treatment. Glucocorticoid is one of the most important drugs in the treatment of asthma in children. Furthermore, the most effective long-term treatment for asthma in children under six years old is the inhalation of glucocorticoids, and lowdose inhaled corticosteroids (ICS) are recommended as the initial control therapy (67). The systemic application of glucocorticoids is the first-line drug for the treatment of severe asthma attacks in children, and its early application can effectively alleviate these conditions and reduce the fatality rate (68). An inhaled $\beta 2$ receptor agonist is a widely used bronchodilator in clinics that can reduce the release of inflammatory mediators, reduce microvascular permeability, and enhance the ciliary function of epithelial cells. Furthermore, this can be used for the long-term maintenance treatment of children with acute asthma attacks and moderate-severe asthma. Leukotriene regulator is a new kind of non-hormone anti-inflammatory drug, which can inhibit leukotriene activity in airway smooth muscles, reduces vascular permeability and bronchospasm, and can be used on its own to treat light asthma attacks, especially in patients with ICS contraindications. In addition, anticholinergic drugs, magnesium sulfate, theophylline, and other drugs also have an apparent effect in achieving remission in the acute stage. In recent years, the monoclonal anti- $\mathrm{IgE}$ antibody omalizumab has been used in the maintenance period of asthma, which can effectively reduce asthma attacks $(69,70)$. Furthermore, anti-IL-4 
and anti-IL-13 monoclonal antibodies would come out in succession.

\section{Similarities in treatments between NS and atopic disease in children}

The above-mentioned analysis revealed that glucocorticoids, immunosuppressants, and biological agents are all used in the treatment of both NS and atopic diseases. Therefore, it was speculated that NS and atopic diseases may be the same kind of disease, have a similar pathogenesis, and only exhibit different clinical manifestations due to the different affected parts of the disease.

\section{Conclusions}

Although NS and atopic diseases in children have different pathological positions and clinical manifestations, these are very similar in pathogenesis and cytokine changes. Furthermore, these have some common points in the treatment. In clinics, some children suffer from NS and atopic disease at the same time or have one of these diseases after the onset of the other. Therefore, the investigators propose that NS in children and other atopic diseases may have the same process in different organs and that NS children may also have atopic dermatitis or allergic rhinitis. In summary, it could be necessary to explore the correlation between these two further. This may provide a new method for the treatment of NS children.

\section{Acknowledgments}

Funding: None.

\section{Footnote}

Conflicts of Interest: All authors have completed the ICMJE uniform disclosure form (available at http://dx.doi. org/10.21037/tau-20-665). The authors have no conflicts of interest to declare.

Ethical Statement: The authors are accountable for all aspects of the work in ensuring that questions related to the accuracy or integrity of any part of the work are appropriately investigated and resolved.

Open Access Statement: This is an Open Access article distributed in accordance with the Creative Commons
Attribution-NonCommercial-NoDerivs 4.0 International License (CC BY-NC-ND 4.0), which permits the noncommercial replication and distribution of the article with the strict proviso that no changes or edits are made and the original work is properly cited (including links to both the formal publication through the relevant DOI and the license). See: https://creativecommons.org/licenses/by-nc$\mathrm{nd} / 4.0 /$.

\section{References}

1. Berghea EC, Balgradean M, Popa IL. Correlation Between Idiopathic Nephrotic Syndrome and Atopy in Children - Short Review. Maedica (Bucur) 2017;12:55-8.

2. Davin JC. The glomerular permeability factors in idiopathic nephrotic syndrome. Pediatr Nephrol 2016;31:207-15.

3. Kanai T, Shiraishi H, Yamagata T, et al. Th2 cells predominate in idiopathic steroid-sensitive nephrotic syndrome. Clin Exp Nephrol 2010;14:578-83.

4. Uwaezuoke SN. Steroid-sensitive nephrotic syndrome in children: triggers of relapse and evolving hypotheses on pathogenesis. Ital J Pediatr 2015;41:19.

5. Dong C. Diversification of t-helper-cell lineages: Finding the family root of IL-17-producing cells. Nat Rev Immunol 2006;6:329-33.

6. Dong C. Th17 cells in development: An updated view of their molecular identity and genetic programming. Nat Rev Immunol 2008;8:337-48.

7. Josefowicz SZ, Lu LF, Rudensky AY. Regulatory T cells: mechanisms of differentiation and function. Annu Rev Immunol 2012;30:531-64.

8. Shao XS, Yang XQ, Zhao XD, et al. The prevalence of Th17 cells and FOXP3 regulate T cells (Treg) in children with primary nephrotic syndrome. Pediatr Nephrol 2009;24:1683-90.

9. Wei CC, Tsai JD, Lin CL, et al. Increased risk of idiopathic nephrotic syndrome in children with atopic dermatitis. Pediatr Nephrol 2014,29:2157-63.

10. Noval Rivas M, Crother TR, Arditi M. The microbiome in asthma. Curr Opin Pediatr 2016;28:764-71.

11. Abdel-Hafez M, Shimada M, Lee PY, et al. Idiopathic nephrotic syndrome and atopy: Is there a common link? Am J Kidney Dis 2009;54:945-53.

12. Gandhi NA, Pirozzi G, Graham NMH. Commonality of the IL-4/IL-13 pathway in atopic diseases. Expert Rev Clin Immunol 2017;13:425-37.

13. Akdis M, Akdis CA. Mechanisms of allergen-specific 
immunotherapy: Multiple suppressor factors at work in immune tolerance to allergens. J Allergy Clin Immun 2014;133:621-31.

14. Abdel-Gadir A, Massoud AH, Chatila TA. Antigenspecific Treg cells in immunological tolerance: implications for allergic diseases. F1000Res 2018;7:38.

15. Small P, Keith PK, Kim H. Allergic rhinitis. Allergy Asthma Clin Immunol 2018;14:51.

16. Looman KIM, van Meel ER, Grosserichter-Wagener C, et al. Associations of Th2, Th17, Treg cells, and IgA+ memory B cells with atopic disease in children: The Generation R Study. Allergy 2020;75:178-87.

17. Fanconi G, Kousmine C, Frisch Knecht W. Prognosis of the nephrosis syndrome. Helv Paediatr Acta 1951;6:219-24.

18. Hardwicke J, Soothill JF, Squire JR, et al. Nephrotic syndrome with pollen hypersensitivity. Lancet 1959;1:500-2.

19. Wittig HJ, Goldman AS. Nephrotic syndrome associated with inhaled allergens. Lancet 1970;1:542-3.

20. Rytand DA. Onset of the nephrotic syndrome during a reaction to bee sting. Stanford Med Bull 1955;13:224-33.

21. Kuzemko JA. Measles vaccination and the nephrotic syndrome. Br Med J 1972;4:665-6.

22. Zellweger F, Eggel A. IgE-associated allergic disorders: Recent advances in etiology, diagnosis, and treatment. Allergy 2016;71:1652-61.

23. Gasser P, Eggel A. Targeting IgE in allergic disease. Curr Opin Immunol 2018;54:86-92.

24. Liu Y, Lai M, Lou Y, et al. Elevation of plasma-soluble HLA-G in childhood nephrotic syndrome is associated with IgE. Ann Clin Biochem 2017;54:69-75.

25. Jahan I, Hanif M, Ali MA, et al. Relationship between serum IgE and frequent relapse idiopathic nephrotic syndrome. Mymensingh Med J 2011;20:484-9.

26. Fuke Y, Endo M, Ohsawa I, et al. Implication of elevated serum IgE levels in minimal change nephrotic syndrome. Nephron 2002;91:769-70.

27. Stangou M, Spartalis M, Daikidou DV, et al. Impact of Th1 and Th2 cytokines in the progression of idiopathic nephrotic syndrome due to focal segmental glomerulosclerosis and minimal change disease. J Nephropathol 2017;6:187-95.

28. Cahenzli J, Balmer ML, McCoy KD. Microbialimmune cross-talk and regulation of the immune system. Immunology 2013;138:12-22.

29. Kool M, Hammad H, Lambrecht BN. Cellular networks controlling Th2 polarization in allergy and immunity. F1000 Biol Rep 2012;4:6.
30. Coers W, Vos JT, Van der Meide PH, et al. Interferongamma (IFN-gamma) and IL-4 expressed during mercuryinduced membranous nephropathy are toxic for cultured podocytes. Clin Exp Immunol 1995;102:297-307.

31. Youn YS, Lim HH, Lee JH. The clinical characteristics of steroid responsive nephrotic syndrome of children according to the serum immunoglobulin E levels and cytokines. Yonsei Med J 2012;53:715-22.

32. Al-Eisa AA, Al Rushood M, Al-Attiyah RJ. Urinary excretion of IL-1beta, IL-6 and IL-8 cytokines during relapse and remission of idiopathic nephrotic syndrome. J Inflamm Res 2017;10:1-5.

33. Youssef DM, Elbehidy RM, El-Shal AS, et al. T helper 1 and $T$ helper 2 cytokines in atopic children with steroid-sensitive nephrotic syndrome. Iran J Kidney Dis 2015;9:298-305.

34. Shalaby SA, Al-Edressi HM, El-Tarhouny SA, et al. Type 1/type 2 cytokine serum levels and role of interleukin-18 in children with steroid-sensitive nephrotic syndrome. Arab J Nephrol Transplant 2013;6:83-8.

35. Kimura A, Naka T, Kishimoto T. IL-6-dependent and -independent pathways in the development of interleukin 17-producing T helper cells. Proc Natl Acad Sci U S A 2007;104:12099-104.

36. Araya C, Diaz L, Wasserfall C, et al. T regulatory cell function in idiopathic minimal lesion nephrotic syndrome. Pediatr Nephrol 2009,24:1691-8.

37. Wan F, Lenardo MJ. The nuclear signaling of NFkappaB: Current knowledge, new insights, and future perspectives. Cell Res 2010;20:24-33.

38. Lama G, Luongo I, Tirino G, et al. T-lymphocyte populations and cytokines in childhood nephrotic syndrome. Am J Kidney Dis 2002;39:958-65.

39. Kaneko K, Tsuji S, Kimata T, et al. Pathogenesis of childhood idiopathic nephrotic syndrome: A paradigm shift from t-cells to podocytes. World J Pediatr 2015;11:21-8.

40. Lambrecht BN, Hammad H, Fahy JV. The cytokines of asthma. Immunity 2019;50:975-91.

41. Wongratanacheewin S. Update of cytokines and genes in asthma and allergic rhinitis. Asian Pac J Allergy Immunol 2014;32:275.

42. Hanazawa T, Antuni JD, Kharitonov SA, et al. Intranasal administration of eotaxin increases nasal eosinophils and nitric oxide in patients with allergic rhinitis. J Allergy Clin Immunol 2000;105:58-64.

43. Bossé $Y$, Rola-Pleszczynski $M$. Controversy surrounding the increased expression of TGF beta 1 in asthma. Respir 
Res 2007;8:66.

44. Kariyawasam HH, Gane SB. Allergen-induced asthma, chronic rhinosinusitis and transforming growth factor- $\beta$ superfamily signaling: mechanisms and functional consequences. Expert Rev Clin Immunol 2019;15:1155-70.

45. Chen S, Jin YT, Zhu ZY, et al. Acupoint application of herbal paste relieves symptoms and naso-mucosal inflammatory response by down-regulating serum TGF- $\beta 1$ in allergic rhinitis rats. Zhen Ci Yan Jiu 2019;44:430-3.

46. Xue JM, Yang LT, Yang G, et al. Protease-activated receptor-2 suppresses interleukin (IL)-10 expression in $\mathrm{B}$ cells via upregulating Bcl2L12 in patients with allergic rhinitis. Allergy 2017;72:1704-12.

47. Jiang XG, Yang XD, Lv Z, et al. Elevated serum levels of TNF- $\alpha, \mathrm{IL}-8$, and ECP can be involved in the development and progression of bronchial asthma. J Asthma 2018;55:111-8.

48. Gittler JK, Shemer A, Suarez-Farinas M, et al. Progressive activation of $\mathrm{T}(\mathrm{H}) 2 / \mathrm{T}(\mathrm{H}) 22$ cytokines and selective epidermal proteins characterizes acute and chronic atopic dermatitis. J Allergy Clin Immunol 2012;130:1344-54.

49. Chan CY, Ng KH, Chen J, et al. Novel role of Vav1-Rac1 pathway in actin cytoskeleton regulation in interleukin13-induced minimal change-like nephropathy. Clin Sci (Lond) 2016;130:2317-27.

50. Laoukili J, Perret E, Willems T, et al. Il-13 alters mucociliary differentiation and ciliary beating of human respiratory epithelial cells. J Clin Invest 2001;108:1817-24.

51. Bagnasco D, Ferrando M, Varricchi G, et al. A Critical Evaluation of Anti-IL-13 and Anti-IL-4 Strategies in Severe Asthma. Int Arch Allergy Immunol 2016;170:122-31.

52. Kim AH, Chung JJ, Akilesh S, et al. B cell-derived IL-4 acts on podocytes to induce proteinuria and foot process effacement. JCI Insight 2017;2:e81836.

53. Pasini A, Benetti E, Conti G, et al. The Italian Society for Pediatric Nephrology (SINePe) consensus document on the management of nephrotic syndrome in children: Part I - Diagnosis and treatment of the first episode and the first relapse. Ital J Pediatr 2017;43:41.

54. Andolino TP, Reid-Adam J. Nephrotic syndrome. Pediatr Rev 2015;36:117-25; quiz 126, 129.

55. Radhakrishnan J, Cattran DC. The KDIGO practice guideline on glomerulonephritis: reading between the (guide)lines--application to the individual patient. Kidney Int 2012;82:840-56.

56. The Subspecialty Group of Renal Diseases, the Society of Pediatrics, Chinese Medical Association. Evidencebased guidelines for diagnosis and treatment of hormonesensitive, relapsed/dependent nephrotic syndrome in children (2016). Chin J Pediatr 2017;55:729-34.

57. Lin CY, Chien JW. Increased interleukin-12 release from peripheral blood mononuclear cells in nephrotic phase of minimal change nephrotic syndrome. Acta Paediatr Taiwan 2004;45:77-80.

58. Suyama K, Kawasaki Y, Miyazaki K, et al. Rituximab and low-dose cyclosporine combination therapy for steroidresistant focal segmental glomerulosclerosis. Pediatr Int 2016;58:219-23.

59. Kallash M, Smoyer WE, Mahan JD. Rituximab Use in the Management of Childhood Nephrotic Syndrome. Front Pediatr 2019;7:178.

60. Guo Y. Consensus on the diagnosis and treatment of atopic dermatitis in Chinese children (2017 edition). Chin J Dermatol 2017;50:784-9.

61. Khattri S, Shemer A, Rozenblit M, et al. Cyclosporine in patients with atopic dermatitis modulates activated inflammatory pathways and reverses epidermal pathology. J Allergy Clin Immunol 2014;133:1626-34. Erratum in: J Allergy Clin Immunol 2014;134:764.

62. Wollenberg A, Barbarot S, Bieber T, et al. Consensusbased European guidelines for treatment of atopic eczema (atopic dermatitis) in adults and children: part I. J Eur Acad Dermatol Venereol 2018;32:657-82. Erratum in: J Eur Acad Dermatol Venereol 2019;33:1436.

63. Wollenberg A, Barbarot S, Bieber T, et al. Consensusbased European guidelines for treatment of atopic eczema (atopic dermatitis) in adults and children: part II. J Eur Acad Dermatol Venereol 2018;32:850-78.

64. Hotze M, Baurecht H, Rodriguez E, et al. Increased efficacy of omalizumab in atopic dermatitis patients with wild-type filaggrin status and higher serum levels of phosphatidylcholines. Allergy 2014;69:132-5.

65. Simpson EL, Bieber T, Guttman-Yassky E, et al. Two Phase 3 Trials of Dupilumab versus Placebo in Atopic Dermatitis. N Engl J Med 2016;375:2335-48.

66. Papadopoulos NG, Arakawa H, Carlsen KH, et al. International consensus on (ICON) pediatric asthma. Allergy 2012;67:976-97.

67. Yang AJ. Interpretation of the guidelines for the diagnosis and prevention of bronchial asthma in children (2016 Edition). Chinese Journal of Medicine 2018;53:253-7.

68. Chinese Academy of Pediatrics Respiratory Group, Editorial Board of the Chinese Journal of Pediatrics. Guidelines for the diagnosis and prevention of bronchial 
asthma in children. Chin J Pediatr 2008;46:745-53.

69. Storms W, Bowdish MS, Farrar JR. Omalizumab and asthma control in patients with moderate-to-severe allergic asthma: a 6-year pragmatic data review. Allergy Asthma Proc 2012;33:172-7.

Cite this article as: Zheng Y, Hou L, Wang XL, Zhao CG, $\mathrm{Du} \mathrm{Y}$. A review of nephrotic syndrome and atopic diseases in children. Transl Androl Urol 2021;10(1):475-482. doi: 10.21037/ tau-20-665
70. Pelaia C, Calabrese C, Terracciano R, et al. Omalizumab, the first available antibody for biological treatment of severe asthma: more than a decade of real-life effectiveness. Ther Adv Respir Dis 2018;12:1753466618810192. 